\title{
ESTIMATIVA DE PODER CALORÍFICO E CARACTERIZAÇÃO PARA USO ENERGÉTICO DE RESÍDUOS DA COLHEITA E DO PROCESSAMENTO DE Pinus taeda
}

\author{
Marina Moura de Souza ${ }^{1}$, Dimas Agostinho da Silva ${ }^{2}$, Roberto Rochadelli $^{3}$, \\ Rosimeire Cavalcante dos Santos ${ }^{4}$ \\ ${ }^{1}$ Eng ${ }^{\mathrm{a}}$ Florestal, M.Sc., UFV, Viçosa, MG, Brasil - marina.moura@ufv.br \\ ${ }^{2}$ Eng. Florestal, Dr., Depto. de Engenharia e Tecnologia Florestal, UFPR, Curitiba, PR, Brasil - dimass@ufpr.br \\ ${ }^{3}$ Eng. Florestal, Dr., Depto. de Veterinária, UFPR, Palotina, PR, Brasil - nashtell@ufpr.br \\ ${ }^{4}$ Eng $^{\mathrm{a}}$ Florestal, Dr ${ }^{\mathrm{a}}$., UFRGN, Natal, RN, Brasil - meirecaico@ yahoo.com.br \\ Recebido para publicação: 30/07/2010 - Aceito para publicação: 12/01/2011
}

\begin{abstract}
Resumo
Este trabalho teve o objetivo de avaliar, mediante caracterização, o aproveitamento de resíduos florestais e madeireiros para fins energéticos. A obtenção dos materiais foi feita em uma empresa que realiza a colheita e o processamento da madeira de Pinus taeda L. situada no município de Tunas do Paraná, PR. Foram identificadas as fontes geradoras dos resíduos do processamento e procedeu-se à coleta dos materiais e do resíduo proveniente da colheita florestal. Os resíduos foram caracterizados de acordo com a umidade, poder calorífico, densidade e teores de carbono fixo e cinzas. Foi feito um ajuste de modelos matemáticos que pudessem expressar a relação entre umidade e poder calorífico para os materiais. As costaneiras e o resíduo da colheita apresentaram elevados teores de umidade e as costaneiras maior densidade e maior teor de carbono fixo. O teor de cinzas foi estatisticamente igual para todos os materiais. O poder calorífico superior se apresentou na faixa de 4.550 e $4.950 \mathrm{kcal} / \mathrm{kg}$, e o poder calorífico útil (material úmido) para as costaneiras e os resíduos da colheita apresentou uma relevante queda, visto o elevado teor de umidade. O modelo de regressão selecionado pôde expressar em mais de $97 \%$ a relação entre poder calorífico e teor de umidade.

Palavras-chave: Resíduos de madeira; uso energético; teor de umidade.
\end{abstract}

\begin{abstract}
Calorific Power estimate and characterization of residues from harvesting and processing of Pinus taeda for energy purposes. This study aimed to evaluate, by characterization, the use of forest and woody residues for energy purposes. The material was collected from a company engaged in wood harvesting and processing of Pinus taeda L., the sources of waste processing have been identified and then it was collect the materials, as well as the residues from forest harvesting. The residues were characterized according to moisture, calorific value, density and levels that fixed carbon and ash. It was done a mathematical adjustment of models that could express the relation between moisture and caloric value for the materials. The slabs and crop residues presented high levels of humidity and the slabs had higher density and higher fixed carbon content. The ash content was statistically equal for all materials. The calorific value was between 4550 and $4950 \mathrm{kcal} / \mathrm{kg}$; the useful calorific value for slabs and crop residues revealed an important decrease caused by high moisture content of these materials. The model of regression selected could express in more than $97 \%$ the relation between caloric value and of moisture content.

Keywords: Forest residues; energetic use; moisture content.
\end{abstract}

\section{INTRODUÇÃO}

Entre as fontes renováveis de energia, insere-se o grupo dos materiais lignocelulósicos, havendo destaque para a biomassa florestal, a qual pode ser diferenciada em três grandes e principais grupos: o material advindo da colheita florestal, os resíduos gerados devido ao processamento da madeira e a madeira oriunda de florestas energéticas. O material procedente da colheita florestal pode ser caracterizado por galhos, folhas, tocos e raízes; já os resíduos do processamento da madeira se 
diversificam amplamente, devido à forma de processamento das toras e do uso final, muito embora haja a geração principalmente de serragem, aparas e cepilhos.

Para a utilização energética da biomassa florestal, é importante levar em consideração as características físicas e químicas do material, pois elas podem influenciar fortemente no rendimento e na manutenção dos equipamentos, principalmente nos que realizam processos de combustão.

$\mathrm{O}$ teor de umidade pode ser considerado uma das características mais relevantes ao se utilizar materiais lignocelulósicos para a geração de energia, tanto em processos termoquímicos, como a combustão e a pirólise, quanto em processos físicos, como a densificação para produção de pellets e briquetes, e biológicos, como a fermentação. Além desse fato, é necessário considerar que o poder calorífico dos materiais lignocelulósicos segue tendências inversamente proporcionais ao conteúdo de água presente nos mesmos.

Brito e Barrichelo (1979) já mencionavam que o uso da madeira e seus derivados como fonte energética era uma atividade de grande interesse, inclusive com a premissa de plantios florestais destinados exclusivamente para essa atividade. Os resíduos lignocelulósicos, além de apresentarem uma relevante capacidade calorífica, são fonte energética potencialmente capaz de substituir algumas formas de combustíveis fósseis, o que pode tornar essa atividade vantajosa (SILVA, 2001).

Farinhaque (1981) concluiu em seu trabalho sobre influência da umidade no poder calorífico da bracatinga (Mimosa scabrella) que há perda de calorias na queima de madeira úmida, devido ao gasto no aquecimento e vaporização da água. Nesse caso, houve uma redução de $57 \%$ do poder calorífico quando a umidade alterou de $0 \%$ para $80 \%$. Ele também ressalta que, para um bom aproveitamento do material para a combustão, ele deve ser utilizado em teores abaixo de $25 \%$, não apenas pela redução do poder calorífico disponível, mas também porque acima desse valor poderá formar crostas e fuligem nas chaminés e no interior da câmara de combustão.

Assim, este estudo teve como objetivo caracterizar, sob o ponto de vista energético, os resíduos provenientes da colheita florestal e do processamento da madeira de Pinus taeda L., bem como ajustar equações que possibilitem averiguar a variação do poder calorífico mediante alterações no teor de umidade dos resíduos.

\section{MATERIAL E MÉTODOS}

\section{Área de estudo}

Este estudo foi realizado em uma serraria localizada na cidade de Tunas do Paraná, estado do Paraná, situada a aproximadamente $80 \mathrm{~km}$ da capital, Curitiba. A serraria realiza o processamento primário das toras, a secagem das tábuas e posteriormente o processamento secundário para a fabricação de peças para a montagem de pellets vendidos para a fabricação de embalagens. A empresa possui produtividade variando entre 54 e $55 \mathrm{~m}^{3}$ de madeira serrada por dia, sendo que a espécie utilizada é o Pinus taeda $\mathrm{L}$.

\section{Material de estudo}

Para esse estudo, foram coletados, primeiramente, o resíduo proveniente da colheita florestal, o qual é cavaqueado e destinado para o abastecimento de uma caldeira geradora de energia para as câmaras de secagem. Da linha de desdobro primário das toras foi coletado o resíduo caracterizado como costaneiras, já cavaqueadas.

Do processamento secundário, ou seja, do processamento das tábuas já secas, foram coletados os materiais caracterizados como refilo, cepilho e pó de serra. Os resíduos foram coletados diretamente na fonte geradora, sendo amostrados três dias aleatórios. Foram coletados aproximadamente $5 \mathrm{~kg}$ de cada material por dia e posteriormente efetuada a mistura e a retirada de amostras significativas.

\section{Caracterização dos resíduos}

Os resíduos da colheita florestal e do processamento das toras foram encaminhados ao Laboratório de Energia da Biomassa da Universidade Federal do Paraná, para determinação da densidade e dos teores de umidade e poder calorífico, conforme descrições a seguir.

Umidade

O teor de umidade dos materiais foi calculado de acordo com a norma da Associação Brasileira de Normas Técnicas (ABNT)/NBR 14929/2003. Para tanto, foi utilizada uma balança com sensibilidade 
de $0,01 \mathrm{~g}$ e uma estufa com temperatura de $103 \pm 2{ }^{\circ} \mathrm{C}$. Foi determinado o teor de umidade assim que os materiais chegaram ao laboratório, para estimar os valores que eles apresentavam no local de coleta.

Densidade

A determinação da densidade aparente foi através da norma ABNT/NBR 14984/2003, com algumas adaptações para pequenas amostras. $\mathrm{O}$ teste de densidade aparente foi realizado utilizando-se uma balança analítica de precisão para a determinação do peso (com a umidade original) das amostras e um cilindro volumétrico para a conferência do volume dos materiais.

Poder calorífico

A determinação do poder calorífico superior foi feito de acordo com a norma ABNT/NBR 8633/84. Utilizou-se uma bomba calorimétrica adiabática modelo IKA-WERNE; C5000. Foi necessária a transformação dos valores de poder calorífico superior para poder calorífico inferior. Esse cálculo foi feito utilizando-se percentual de hidrogênio presente no material como $6 \%$.

Análise química imediata

Foi realizada de acordo com a norma ABNT/NBR 8112/86 para determinação de materiais voláteis, teor de cinzas e carbono fixo. Foi utilizada balança analítica e mufla com controle de aquecimento.

\section{Análises estatísticas e ajuste de equações}

A análise estatística foi efetuada utilizando-se estatística descritiva, análise de variância e análise de regressão. As variáveis referentes à caracterização dos resíduos foram analisadas estatisticamente através da análise de variância (ANOVA) e teste de "Tukey", ao nível de 95\%. Para o teor de umidade, foram realizadas 10 repetições, para se tentar caracterizar todo o material; para a densidade foram feitas 3 repetições, haja vista a homogeneidade dimensional de cada resíduo; e para o poder calorífico, 2 repetições, de acordo com a atividade do calorímetro.

Para gerar dados que possibilitassem o ajuste de equações representativas da relação entre o poder calorífico e o teor de umidade dos materiais, foi necessário primeiramente o ajuste dos teores de umidade e posteriormente o cálculo dos valores de poder calorífico em cada umidade. Para o ajuste dos teores de umidade, foi necessária inicialmente a secagem completa dos resíduos em estufa, visto que cada um apresentou diferentes níveis de umidade inicial. Os materiais secos foram umedecidos de acordo com os teores de umidade base seca, pré-definidos, em que se desejava averiguar o poder calorífico.

Foram separadas, por recipiente, amostras de 2,0 g de cada material e em cada um foi adicionada uma massa de água referente à umidade desejada. Para melhor representar os teores de umidade, foram consideradas classes de 5 unidades de amplitude. Dessa forma, foi calculada a massa de água, mediante o centro de classe da umidade desejada. Foi considerado o material seco (0\%) até a classe de 155 a $160 \%$ (centro 157,5\%), visto que Silva (2001) justifica que a madeira é combustível até 160\% de umidade base seca.

Esse valor de umidade máxima, no caso $160 \%$ na base seca, foi utilizado apenas para o ajuste das equações do resíduo da colheita e das costaneiras, pois esses materiais foram coletados com maiores teores de umidade. Já para o cepilho, refilo e pó de serra, a umidade máxima considerada foi de $80 \%$ base seca.

A variável considerada como dependente é o poder calorífico inferior, e a independente é o teor de umidade na base seca. Foram apresentados os modelos de equações de regressão e polinomial mais adequados para estimar o poder calorífico dos resíduos, mediante observação da tendência dos dados. Na relação dos modelos foram usadas as estimativas dos coeficientes dos melhores modelos testados, bem como seus respectivos coeficientes de determinação ajustados ( $R^{2}$ aj.), erro-padrão da estimativa em percentagem (Sxy\%) e análise dos resíduos dos erros.

\section{RESULTADOS E DISCUSSÕES}

\section{Caracterização dos resíduos da colheita florestal e do processamento da madeira Umidade}

Os resultados médios para os valores de umidade dos resíduos estudados estão apresentados na tabela 1, bem como os respectivos coeficientes de variação e testes de médias. 
Tabela 1. Teores de umidade médios na base seca (Ubs) e respectivos testes de médias e coeficientes de variação $(\mathrm{CV})$ para os resíduos da floresta e do processamento da madeira.

Table 1. Dry bases moisture content (Ubs), average test and variation coefficient for the forest and wood processing residues.

\begin{tabular}{lccc}
\hline Procedência & Material & Ubs (\%) & CV(\%) \\
\hline Processamento & Costaneira & $91,81(\mathrm{a})$ & 5,89 \\
Floresta & Resíduo colheita & $63,36(\mathrm{~b})$ & 9,63 \\
Processamento & Refilo & $10,64(\mathrm{c})$ & 1,42 \\
Processamento & Pó de serra & $8,80(\mathrm{c})$ & 2,53 \\
Processamento & Cepilho & $7,14(\mathrm{c})$ & 13,89 \\
\hline Nota: Médias seguidas de mesma letra não diferem estatisticamente entre si ao nível de 5\% de probabilidade pelo teste de Tukey.
\end{tabular}

Pode-se observar na tabela 1 que houve a distinção de três grupos, de acordo com a umidade média. As costaneiras provenientes do processamento da madeira apresentaram a maior média, seguidas pelos resíduos vindos da colheita florestal e pelos resíduos do processamento da madeira referentes ao processamento das tábuas já secas.

Os resultados obtidos para os resíduos do processamento da madeira já eram esperados, visto as condições de processamento primário e secundário. Já o resíduo proveniente da colheita florestal obteve valores de umidade menores que os esperados, haja vista que, quando se procede à colheita florestal, as toras podem apresentar conteúdo de água acima de $100 \%$. Assim, pode-se supor que esse material permaneceu no campo após a colheita, dando tempo para que ocorresse uma secagem parcial, pois, de acordo com Brand (2007), o tempo de estocagem tem influência sobre o teor de umidade, sendo que há uma variação significativa da umidade com relação ao período de estocagem. A autora evidencia que o teor de água foi alto no material recém-coletado, diminuiu nos primeiros quatro meses de estocagem e voltou a aumentar após esse período.

Densidade

Os resultados médios para a densidade aparente dos resíduos coletados estão apresentados na tabela 2 , bem como os respectivos coeficientes de variação e testes de médias.

Tabela 2. Valores médios de densidade aparente e respectivos testes de médias e coeficientes de variação (CV) para os resíduos da floresta e do processamento da madeira.

Table2. Average values of density, average tests and variation coefficients for the forest and wood residues respectively.

\begin{tabular}{lccc}
\hline Procedência & Material & Densidade aparente $\left(\mathbf{g} / \mathbf{c m}^{\mathbf{3}}\right)$ & $\mathbf{C V}(\mathbf{\%})$ \\
\hline Processamento & Costaneira & $0,347(\mathrm{a})$ & 1,83 \\
Floresta & Resíduo colheita & $0,235(\mathrm{~b})$ & 2,33 \\
Processamento & Refilo & $0,187(\mathrm{c})$ & 4,26 \\
Processamento & Cepilho & $0,180(\mathrm{c})$ & 0,82 \\
Processamento & Pó de serra & $0,161(\mathrm{~d})$ & 3,41 \\
\hline Nota: Médias seguidas de mesma letra não diferem estatisticamente entre si ao nível de 5\% de probabilidade pelo teste de Tukey.
\end{tabular}

Pode-se observar a presença de 4 grupos distintos, sendo que apenas cepilho e refilo apresentam valores significativamente iguais de densidade. O resíduo costaneira apresentou maior valor de densidade, o que pode ser explicado aparentemente pela presença de cascas nele, além da maior umidade apresentada. $\mathrm{O}$ resíduo da colheita deveria apresentar a densidade estatisticamente igual à costaneira, devido à presença de cascas, porém isso não foi observado, possivelmente pela presença de árvores mortas e tocos velhos nesse material.

Poder calorífico

Na tabela 3 são apresentados os valores médios para o poder calorífico, o poder calorífico útil dos resíduos coletados e também os respectivos coeficientes de variação e testes de médias.

Mediante os dados apresentados na tabela 3, pode-se ressaltar que, de acordo com o poder calorífico superior, há a presença de dois grupos estatisticamente diferentes. As maiores médias foram obtidas com os materiais cepilho e resíduo da colheita. Com relação ao poder calorífico útil dos materiais, 
observa-se que o resíduo da colheita foi o que apresentou as menores médias, o que claramente é explicado pelo alto teor de umidade destes no momento da coleta.

Tabela 3. Valores médios para o poder calorífico superior, inferior e útil para os resíduos em estudo. Table 3. Average values of high calorific power, lower and useful for the focused residues.

\begin{tabular}{lcccccc}
\hline \multirow{2}{*}{ Procedência } & \multirow{2}{*}{ Material } & Ubs & PCS & PCI & PCLu & CV \\
\cline { 3 - 7 } & & $(\boldsymbol{\%})$ & & kcal/kg & & $(\boldsymbol{\%})$ \\
\hline Processamento & Cepilho & 7,14 & $4926(\mathrm{a})$ & 4602 & 4255 & 0,8 \\
Floresta & Res. colheita & 63,36 & $4902(\mathrm{a})$ & 4578 & 2570 & 0,45 \\
Processamento & Pó de serra & 8,8 & $4747(\mathrm{ab})$ & 4423 & 4017 & 0,07 \\
Processamento & Costaneira & 91,81 & $4731(\mathrm{ab})$ & 4407 & 2010 & 0,03 \\
Processamento & Refilo & 10,64 & $4535(\mathrm{~b})$ & 4211 & 3748 & 2,81 \\
\hline
\end{tabular}

Nota: Médias seguidas de mesma letra não diferem estatisticamente entre si ao nível de 5\% de probabilidade pelo teste de Tukey.

Os valores de poder calorífico superior conferem com os de Kollmann e Côte (1968), que afirmam que o poder calorífico da madeira seca, sem considerar o erro de cinzas, pode ser tomado com um valor médio de $4.500 \mathrm{kcal} / \mathrm{kg}$. Os valores tanto de densidade quanto de poder calorífico para as costaneiras são condizentes com Fontes (1994), que encontrou, para resíduos úmidos do processamento de Pinus spp., poder calorífico inferior, com média de 2.9094,39 e densidade média de $0,38 \mathrm{~g} / \mathrm{cm}^{3}$.

Fontes (1994), caracterizando energeticamente a madeira de Pinus sp., obteve o poder calorífico médio na ordem de 2246,93 kcal $/ \mathrm{kg}$ para a serragem e de 2592,85 para os cavacos. Para a densidade foram encontrados valores médios de $380 \mathrm{~kg} / \mathrm{m}^{3}$ para ambos os materiais. Balloni (2009) obteve $4.323 \mathrm{kcal} / \mathrm{kg}$ de poder calorífico obtido a $0 \%$ de umidade para a madeira de Pinus elliottii. Brito (1993) afirma que a variação do poder calorífico superior para a madeira em geral está entre $3.500 \mathrm{kcal} / \mathrm{kg}$ e $5.000 \mathrm{kcal} / \mathrm{kg}$.

A densidade básica mostrou-se na faixa dos valores obtidos em outros estudos para as árvores da família das coníferas, com uma densidade básica média de 0,470 g/ $\mathrm{cm}^{3}$. Andrew e Burley (1972) observaram densidade básica média de $0,48 \mathrm{~g} / \mathrm{cm}^{3}$ para árvores de pínus com idades variando entre $16 \mathrm{e}$ 18 anos. De acordo com Rosa (2003), a madeira mais procurada atualmente para conversão em pasta celulose é a que apresenta uma densidade ótima, a qual se encontra entre 0,450 e $0,550 \mathrm{~g} / \mathrm{cm}^{3}$.

Análise química imediata

Os valores médios para os teores de materiais voláteis, carbono fixo e cinzas para os cinco resíduos estudados estão apresentados na tabela 4, bem como os respectivos coeficientes de variação e testes de médias.

Tabela 4. Valores médios para os componentes da análise química imediata e respectivos testes de médias e coeficientes de variação (CV\%) para os resíduos da floresta e do processamento da madeira.

Table 4. Average values for the immediate chemical analysis and average tests and variation coefficient $(\mathrm{CV} \%)$ for the forest and wood residues.

\begin{tabular}{lccccccc}
\hline \multirow{2}{*}{ Procedência } & \multirow{2}{*}{ Material } & \multicolumn{2}{c}{ Materiais voláteis } & \multicolumn{2}{c}{ Carbono fixo } & \multicolumn{2}{c}{ Cinzas } \\
\cline { 2 - 7 } & & Média (\%) & $\mathbf{C V}(\%)$ & Média (\%) & CV(\%) & Média (\%) & CV(\%) \\
\hline Processamento & Costaneira & 82,57 (a) & 0,67 & 17,01 (a) & 3,92 & 0,42 (a) & 26,94 \\
Floresta & Res. colheita & 85,09 (b) & 0,10 & 14,06 (b) & 0,17 & 0,20 (a) & 30,07 \\
Processamento & Cepilho & 85,09 (b) & 0,92 & 14,01 (b) & 5,91 & 0,30 (a) & 26,03 \\
Processamento & Refilo & 84,90 (b) & 0,26 & 14,80 (b) & 1,73 & 0,30 (a) & 12,20 \\
Processamento & Pó de serra & 86,24 (b) & 0,02 & 13,44 (b) & 1,01 & 0,31 (a) & 36,70 \\
\hline
\end{tabular}

Nota: Médias seguidas de mesma letra não diferem estatisticamente entre si ao nível de 5\% de probabilidade pelo teste de Tukey.

Primeiramente, com relação aos valores para materiais voláteis e carbono fixo, foram apresentados dois grupos estatisticamente diferentes, sendo apenas o resíduo costaneira diferente dos demais. As maiores médias encontradas para esse resíduo podem ser influenciadas mais uma vez pela presença de cascas, porém ainda estão dentro dos valores normalmente observados.

Pode-se observar que todos os materiais são estatisticamente iguais para o teor de cinzas, o que pode ser ressaltado como uma característica positiva para a utilização deles em caldeiras. Vale ressaltar também que os valores de CV\% para os teores de cinzas são bem maiores que para os demais componentes. Isso pode ser 
explicado devido ao fato de o valor numérico referente ao teor de cinzas ser pequeno. Embora não significativo, o maior conteúdo de cinzas pode ser explicado devido à fração de casca no material costaneiras.

\section{Modelos de regressão para estimativa do poder calorífico dos resíduos}

Dispersão e tendência dos dados

Na figura 1 são apresentadas a dispersão dos dados e suas curvas de tendência para os resíduos em estudo. Pode-se observar a tendência inversamente proporcional entre o poder calorífico e o teor de umidade dos materiais coletados.
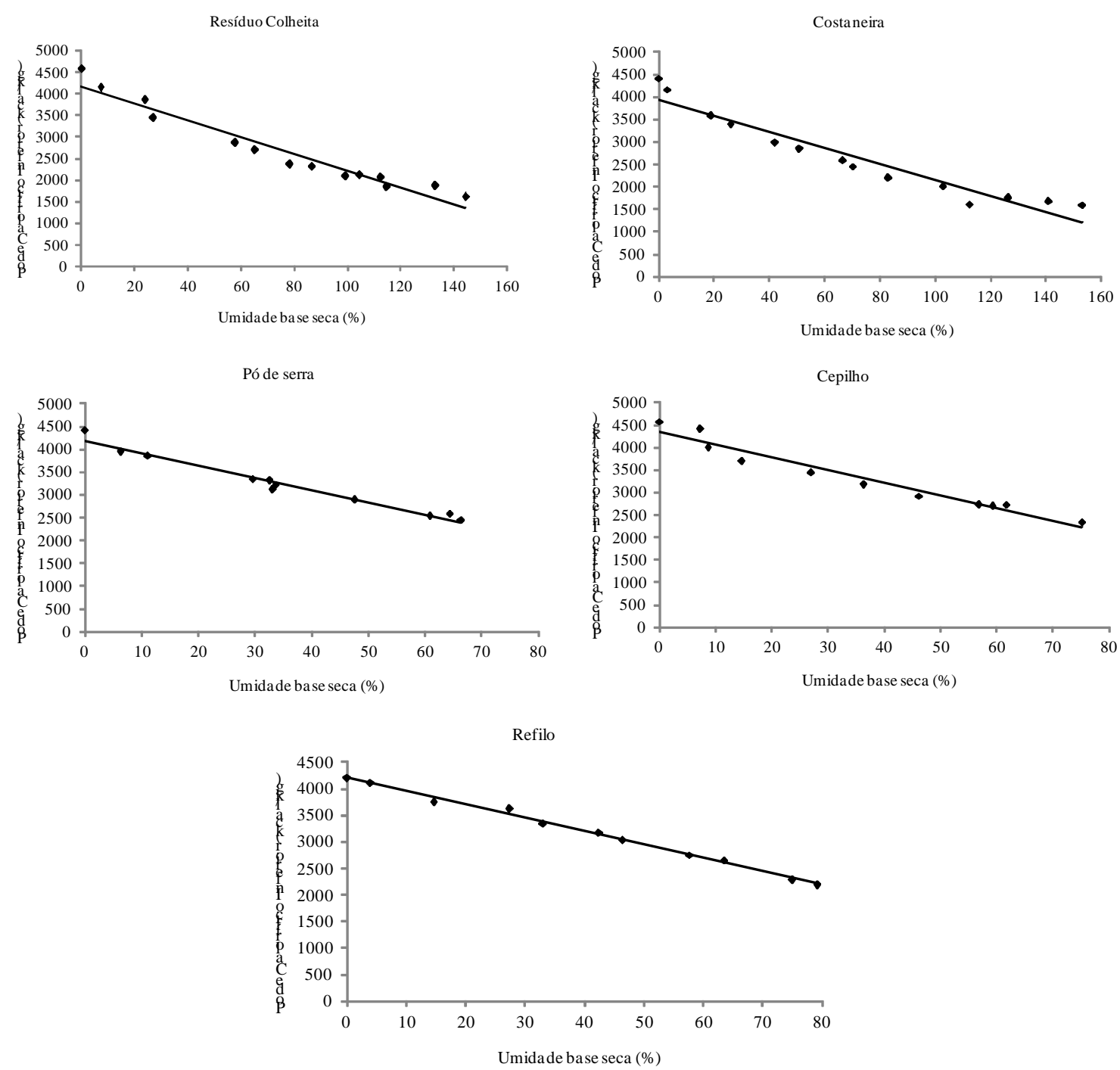

Figura 1. Relação entre poder calorífico e teor de umidade para os resíduos da colheita florestal e do processamento da madeira.

Figure 1. Relationship between calorific power and moisture content for the forest and wood residues.

Esta relação entre poder calorífico é bastante conhecida e pode ser confirmada pelos estudos de Kollmann e Cotê (1968), que apresentam, da mesma forma, o poder calorífico inferior em função da umidade da madeira, demonstrando que o quanto maior o teor de umidade presente na madeira, menor será sua capacidade de combustão. 
Seleção de modelos

Os modelos foram desenvolvidos para serem aplicados utilizando resíduos da colheita e do processamento da madeira de Pinus taeda, com o objetivo de se determinar o poder calorífico inferior desses materiais. Todos os modelos apresentaram valores de F significativos ( $\mathrm{p}<0,01)$. Os valores dos coeficientes de determinação encontrados foram bons. Nas tabelas 5 a 9 são apresentados os modelos estudados.

Tabela 5. Relação dos modelos estudados para estimativa do poder calorífico dos resíduos da colheita florestal.

Table 5. Relationship of the studied models for estimate calorific power of the harvest forest residues.

\begin{tabular}{lcccccc}
\hline $\begin{array}{l}\text { Variável } \\
\text { resposta (Y) }\end{array}$ & Modelos & $\mathbf{a}$ & $\mathbf{b}$ & $\mathbf{c}$ & $\mathbf{R}_{\text {aj. }}^{2}$ & $\mathbf{S}_{\mathbf{y x}} \%$ \\
\hline & $\mathrm{Y}=\mathrm{a}+\mathrm{bx}+\mathrm{cx}^{2}$ & $\begin{array}{c}4473,46 \\
\mathrm{t}=62,8071\end{array}$ & $\begin{array}{c}-34,0764 \\
\mathrm{t}=-4,7309\end{array}$ & $\begin{array}{c}0,103823 \\
\mathrm{t}=6,48976\end{array}$ & 0,9871 & 3,93 \\
\cline { 2 - 7 } & $\mathrm{Y}=\exp (\mathrm{a}+\mathrm{bx})$ & $\begin{array}{c}8,37623 \\
\mathrm{t}=352,89\end{array}$ & $\begin{array}{c}-0,0069714 \\
\mathrm{t}=-25,5976\end{array}$ & - & 0,9807 & 3,62 \\
\cline { 2 - 7 } $\begin{array}{l}\text { Poder calorífico } \\
\text { (kcal/kg) }\end{array}$ & $\mathrm{Y}=1 /(\mathrm{a}+\mathrm{bx})$ & $\begin{array}{c}0,000210205 \\
\mathrm{t}=22,4832\end{array}$ & $\begin{array}{c}0,00000262695 \\
\mathrm{t}=24,5976\end{array}$ & - & 0,9789 & 3,61 \\
\cline { 2 - 8 } & $\mathrm{Y}=\mathrm{a}+(\mathrm{raizx})$ & $\begin{array}{c}4799,16 \\
\mathrm{t}=51,6111\end{array}$ & $\begin{array}{c}-262,455 \\
\mathrm{t}=-24,4701\end{array}$ & - & 0,9787 & 3,61 \\
\cline { 2 - 8 } & $\mathrm{Y}=(\mathrm{a}+\mathrm{bx})^{\wedge 2}$ & $\begin{array}{c}65,1615 \\
\mathrm{t}=78,163635\end{array}$ & $-19,2838$ & - &, 09661 & 3,57 \\
\hline
\end{tabular}

Tabela 6. Relação dos modelos estudados para estimativa do poder calorífico para as costaneiras.

Table 6. Relationship of the studied models for estimate slabs calorific power.

\begin{tabular}{|c|c|c|c|c|c|c|}
\hline $\begin{array}{l}\text { Variável } \\
\text { resposta (Y) }\end{array}$ & Modelos & $\mathbf{a}$ & $\mathbf{b}$ & c & $\mathbf{R}_{\text {aj. }}^{2}$ & $\mathrm{~S}_{\mathrm{yx}} \%$ \\
\hline \multirow{5}{*}{$\begin{array}{l}\text { Poder calorífico } \\
(\mathrm{kcal} / \mathrm{kg})\end{array}$} & $Y=a+b x+c x^{2}$ & $\begin{array}{c}4292,01 \\
t=72,1202\end{array}$ & $\begin{array}{c}-34,4697 \\
\mathrm{t}=-18,1797\end{array}$ & $\begin{array}{c}0,111166 \\
t=9,0796\end{array}$ & 0,9897 & 3,71 \\
\hline & $\mathrm{Y}=\mathrm{a}+($ raizx $)$ & $\begin{array}{c}4563,07 \\
t=58,7623\end{array}$ & $\begin{array}{c}248,938 \\
t=-27,0295\end{array}$ & - & 0,9825 & 3,68 \\
\hline & $Y=\exp (a+b x)$ & $\begin{array}{c}8,31513 \\
t=256,948\end{array}$ & $\begin{array}{l}-0,00680107 \\
t=-18,1077\end{array}$ & - & 0,9617 & 3,61 \\
\hline & $\mathrm{Y}=1 /(\mathrm{a}+\mathrm{bx})$ & $\begin{array}{c}0,000224033 \\
t=16,8802\end{array}$ & $\begin{array}{c}0,00000275023 \\
t=17,8543\end{array}$ & - & 0,9607 & 3,60 \\
\hline & $Y=(a+b x)^{\wedge^{2}}$ & $\begin{array}{c}63,2233 \\
t=64,0772\end{array}$ & $\begin{array}{c}-0,173185 \\
t=-15,1232\end{array}$ & - & 0,9459 & 3,58 \\
\hline
\end{tabular}

Tabela 7. Relação dos modelos estudados para estimativa do poder calorífico para o pó de serra.

Table 7. Relationship of the studied models for estimate saw powder calorific power.

\begin{tabular}{lcccccc}
\hline $\begin{array}{l}\text { Variável } \\
\text { resposta (Y) }\end{array}$ & Modelos & $\mathbf{a}$ & $\mathbf{b}$ & $\mathbf{c}$ & $\mathbf{R}_{\text {aj. }}{ }^{2}$ & $\mathbf{S}_{\mathbf{y x}} \%$ \\
\hline \multirow{2}{*}{$\begin{array}{l}\text { Poder calorífico } \\
\text { (kcal/kg) }\end{array}$} & $\mathrm{Y}=\mathrm{a}+\mathrm{bx}+\mathrm{cx}^{2}$ & $\begin{array}{c}4311,2 \\
\mathrm{t}=68,7508\end{array}$ & $\begin{array}{c}-38,4919 \\
\mathrm{t}=-9,24571\end{array}$ & $\begin{array}{c}0,167262 \\
\mathrm{t}=2,88358\end{array}$ & 0,9823 & 3,02 \\
\cline { 2 - 7 } & $\mathrm{Y}=\exp (\mathrm{a}+\mathrm{bx})$ & $\begin{array}{c}8,35859 \\
\mathrm{t}=618,901\end{array}$ & $\begin{array}{c}-0,00825877 \\
\mathrm{t}=-25,3029\end{array}$ & - & 0,9846 & 3,03 \\
\cline { 2 - 7 } & $\mathrm{Y}=1 /(\mathrm{a}+\mathrm{bx})$ & $\begin{array}{c}0,000227683 \\
\mathrm{t}=51,1989\end{array}$ & $\begin{array}{c}0,00000258505 \\
\mathrm{t}=24,0528\end{array}$ & - & 0,9830 & 3,02 \\
\cline { 2 - 7 } & $\mathrm{Y}=(\mathrm{a}+\mathrm{bx})^{\wedge}$ & $\begin{array}{c}65,0029 \\
\mathrm{t}=142,907\end{array}$ & $\begin{array}{c}-0,235272 \\
\mathrm{t}=-21,4023\end{array}$ & - & 0,9786 & 3,01 \\
\cline { 2 - 7 } & $\mathrm{Y}=\mathrm{a}+($ raizx $)$ & $\begin{array}{c}4572,67 \\
\mathrm{t}=57,3909\end{array}$ & $\begin{array}{c}-245,122 \\
\mathrm{t}=-18,2082\end{array}$ & - & 0,9706 & 2,99 \\
\hline
\end{tabular}


Tabela 8. Relação dos modelos estudados para estimativa do poder calorífico para o cepilho.

Table 8. Relationship of the studied models for estimate sawdust calorific power.

\begin{tabular}{|c|c|c|c|c|c|c|}
\hline $\begin{array}{c}\text { Variável } \\
\text { resposta (Y) }\end{array}$ & Modelos & $\mathbf{a}$ & b & c & $\mathbf{R}_{\text {aj. }}^{2}$ & $\mathrm{~S}_{\mathrm{yx}} \%$ \\
\hline \multirow{5}{*}{$\begin{array}{l}\text { Poder calorífico } \\
\qquad(\mathrm{kcal} / \mathrm{kg})\end{array}$} & $Y=a+b x+c x^{2}$ & $\begin{array}{c}4521,29 \\
t=50,0958\end{array}$ & $\begin{array}{c}-45,579 \\
\mathrm{t}=-7,25154\end{array}$ & $\begin{array}{c}0,239161 \\
t=2,83426\end{array}$ & 0,9701 & 2,09 \\
\hline & $\mathrm{Y}=1 /(\mathrm{a}+\mathrm{bx})$ & $\begin{array}{l}0,00021987 \\
t=46,2821\end{array}$ & $\begin{array}{c}0,00000259774 \\
t=23,7385\end{array}$ & - & 0,9825 & 2,94 \\
\hline & $\mathrm{Y}=\exp (\mathrm{a}+\mathrm{bx})$ & $\begin{array}{c}8,39496 \\
t=447,11\end{array}$ & $\begin{array}{l}-0,00847168 \\
t=-19,5873\end{array}$ & - & 0,9745 & 2,91 \\
\hline & $Y=(a+b x)^{\wedge^{2}}$ & $\begin{array}{c}66,2233 \\
t=100,8\end{array}$ & $\begin{array}{c}-0,24223 \\
t=-16,1378\end{array}$ & - & 0,9629 & 2,88 \\
\hline & $\mathrm{Y}=\mathrm{a}+($ raizx $)$ & $\begin{array}{c}4803,98 \\
t=46,4932\end{array}$ & $\begin{array}{c}-271,2 \\
t=-15,6895\end{array}$ & & 0,9608 & 2,87 \\
\hline
\end{tabular}

Tabela 9. Relação dos modelos estudados para estimativa do poder calorífico para o refilo.

Table 9. Relationship of the studied models for estimate slabs calorific power for the costaneiras.

\begin{tabular}{|c|c|c|c|c|c|c|}
\hline $\begin{array}{l}\text { Variável } \\
\text { resposta (Y) }\end{array}$ & Modelos & $\mathbf{a}$ & b & c & $\mathbf{R}^{2}{ }_{\text {aj. }}$ & $\mathrm{S}_{\mathrm{yx}} \%$ \\
\hline \multirow{5}{*}{$\begin{array}{l}\text { Poder calorífico } \\
(\mathrm{kcal} / \mathrm{kg})\end{array}$} & $Y=a+b x+c x^{2}$ & $\begin{array}{c}4192,91 \\
t=111,159\end{array}$ & $\begin{array}{c}-23,6145 \\
t=-10,7296\end{array}$ & $\begin{array}{c}-0,020008 \\
t=-0,74476\end{array}$ & 0,9940 & 2,62 \\
\hline & $Y=a+b x$ & $\begin{array}{c}4210,33 \\
t=145,949\end{array}$ & $\begin{array}{c}-25,1878 \\
t=-41,8159\end{array}$ & - & 0,9943 & 3,11 \\
\hline & $Y=(a+b x)^{\wedge^{2}}$ & $\begin{array}{c}65,2684 \\
t=195,099\end{array}$ & $\begin{array}{l}-0,224456 \\
t=-32,133\end{array}$ & - & 0,9904 & 3,10 \\
\hline & $Y=\exp (a+b x)$ & $\begin{array}{c}8,37222 \\
t=499,632\end{array}$ & $\begin{array}{l}-0,00805447 \\
t=-23,0205\end{array}$ & - & 0,9814 & 3,07 \\
\hline & $\mathrm{Y}=1 /(\mathrm{a}+\mathrm{bx})$ & $\begin{array}{l}0,000220496 \\
t=233,8325\end{array}$ & $\begin{array}{c}0,0000026462 \\
t=13,698\end{array}$ & & 0,9491 & 2,97 \\
\hline
\end{tabular}

Modelo selecionado

O modelo selecionado para estimar o poder calorífico inferior dos resíduos da colheita florestal e do processamento da madeira de Pinus taeda foi o polinomial de $2^{\circ}$ grau $\left(\mathrm{Y}=\mathrm{a}+\mathrm{bx}+\mathrm{cx}^{2}\right)$. Embora todos os modelos mostrados tenham obtido um bom desempenho, este foi escolhido devido ao fato de apresentar valores de $\mathrm{R}^{2}$ aj.relativamente próximos para todos os resíduos e também pelo $\mathrm{Syx} \%$ se apresentar com baixos valores.

\section{CONCLUSÕES}

Com relação à caracterização do material:

- As costaneiras e o resíduo da floresta apresentaram os maiores teores de umidade, não sendo indicados para o uso como fonte energética "in natura".

- As costaneiras apresentaram a maior densidade.

- O poder calorífico superior dos resíduos foi observado entre a faixa de 4550 e $4950 \mathrm{kcal} / \mathrm{kg}$, e o poder calorífico útil das costaneiras e dos resíduos da colheita apresentou uma relevante queda, dado o teor de umidade desses materiais.

- Apenas as costaneiras se mostraram significativamente diferentes dos demais resíduos com relação ao teor de materiais voláteis e carbono fixo.

- O teor de cinzas foi estatisticamente igual para todos os resíduos.

Com relação ao ajuste das equações:

- As equações estudadas demonstraram um bom ajuste para todos os resíduos.

- O modelo selecionado expressa com mais de $97 \%$, para todos os resíduos, a relação entre poder calorífico e umidade. 


\section{REFERÊNCIAS}

ANDREW, I. A.; BURLEY, J. Variation of wood quality of Pinus merkusii jungh and de vriese: five trees 16-1 years old in Zambia. Journal of Agricultural, Rhodesian, v. 10, n. 2, p. 183 - 202, 1972.

ASSOCIAÇÃO BRASILEIRA DE NORMAS TÉCNICAS (ABNT). Análise química imediata do carvão vegetal, NBR 8112. 1986. 5 p.

. Determinação do poder calorífico superior, NBR 8633. 1984. 13p.

Madeira - Determinação do teor de umidade de cavacos - Método por secagem em estufa, NBR 14929. 2003. 17p.

. Madeira - Determinação da densidade aparente de cavacos, NBR 14984. 2003. 5p.

BALLONI, C. J. V. Caracterização física e química da madeira de Pinus elliottii. 42 f. (Trabalho de Graduação) - Universidade Estadual Paulista “Júlio de Mesquita Filho”, Itapeva, 2009.

BRAND, M. A. Qualidade da biomassa florestal para o uso na geração de energia em função da estocagem. 169 f. Tese (Doutorado em Ciências Florestais) - Universidade Federal do Paraná, Curitiba, 2007.

BRITO, J. O. Expressão da produção florestal em unidades energéticas. In: 7 Congresso Florestal Brasileiro e I Congresso Florestal Panamericano, Curitiba, 19-24/setembro/1993. Anais..., Curitiba, 1993. p. 280.

BRITO, J. O.; BARRICHELO, L. E. G. Usos diretos e propriedades da madeira para a geração de energia. Disponível em: < http://www.ipef.br/publicacoes/ctecnica/nr052.pdf>. Acesso em: 15/10/2009.

FARINHAQUE, R. Influência da umidade no poder calorífico da madeira de bracatinga (Mimosa scabrella, Benth) e aspectos gerais da combustão. FUPEF, Seria Técnica n ${ }^{\circ}$ 6, Curitiba, 1981.

FONTES, P. J. P. Autossuficiência energética em serraria de Pinus e aproveitamento de resíduos. 93 f. Dissertação (Mestrado em Ciências Florestais) - Universidade Federal do Paraná, Curitiba, 1994.

KOLlmanN, F. F. P.; COTÊ, W. A. Principles of wood science and technology, 2 vol. Berlin: Springer Verlag, 1968.

ROSA, C. A. B. Influência do teor de lignina da madeira de Eucalyptus globulus na produção e na qualidade da celulose kraft. 150 f. Dissertação (Mestrado em Engenharia Florestal/Tecnologia de Produtos Florestais) - Universidade Federal de Santa Maria, Santa Maria, 2003.

SILVA, D. Avaliação da eficiência energética em uma indústria de painéis compensados. 182 f. Tese (Doutorado em Ciências Florestais) - Universidade Federal do Paraná, Curitiba, 2001. 
